\title{
Environmental analysis of cities with hot climate and rugged terrain
}

\author{
Botir Giyasov ${ }^{1}$, and Irina Giyasova ${ }^{1}$ \\ ${ }^{1}$ Moscow State University of Civil Engineering, 129337,26 Yaroslavskoe shosse,, Moscow, \\ Russia
}

\begin{abstract}
Having hot windless climate and rugged terrain resulting from the lack of sufficient aeration, southern cities are in extreme environmental conditions. Urban construction on a rugged terrain affects the established local microclimate by changing the structure of the environment and hydrogeological conditions. In addition, the development of urban space and the construction of modern high-rise buildings significantly affect the aerodynamics of the environment. In hot climate, the urban environment has stable zones suffering from lack of natural air circulation and high concentration of harmful emissions. The article analyzes the factors that aggravate the environmental situation of cities with a rugged terrain and high temperatures. Insufficient aeration and high intensity of solar radiation in the urban environment are identified as the main factors of unfavorable environment in cities with rugged terrain. Based on the analysis of the climatic parameters of the cities of Sochi, Makhachkala and field observations in the city of Dushanbe, we identified conditions under which local air circulation is formed, contributing to the improvement in the environmental situation. The aeration formation models for urban space with different landscaping options are built. The analysis will enable to make the accurate assessment of the factors affecting the formation of aeration of thermal origin and their role in improving the environment of cities with hot, windless climate.
\end{abstract}

\section{Introduction}

Modern cities and megacities, with certain environmental conditions and a specific type of economic development, require special attention from an environmental perspective. As a result of urbanization, the modern urban environment is undergoing constant changes: the density of urban space is increasing, transport and engineering infrastructure is developing, which leads to overpopulation and aggravates the established climate of the area and the environment [1]. In this regard, urban planning on a rugged terrain is of great interest. It is economically feasible to develop cities in unused places, such as territories with rugged terrain.

Being a natural factor, the terrain affects the development of cities and has a direct impact on many aspects of urban development. City designing and building on a complex terrain leads to a transformation of the terrain, a change in hydrogeological conditions and the natural environment. Therefore, in order to maintain the environmental balance, with the high-altitude organization of the built-up territory, it is necessary to maximize the 
preservation of the existing terrain, soil, vegetation, and natural surface forms. The tasks of adjusting the terrain for building purposes are inextricably linked with the problems of protecting the environment and natural resources $[2,3]$.

The issue of the formation of special climatic conditions and a change in the environment in rugged terrain is particularly acute for cities with hot climate. Almost the most part of Central Asia, the territory of Transcaucasia and Russia belong to cities with rugged topography and hot climate. The significant intensity of solar radiation, characteristic of these territories, combined with high temperatures, high probability of sunshine and low air mobility significantly aggravates the environmental situation there. Under such conditions, a high level of temperature-radiation heating is observed, and significant thermal loads are created on the natural environment and the human body [4]. In addition, low air mobility contributes to the concentration of harmful substances in a residential environment. These factors significantly reduce the efficiency, productivity of physical and mental labor. Maintaining a favorable microclimate and ecology in the residential environment of cities with hot climate and rugged terrain is an important but difficult task.

Thus, a serious environmental situation is observed in cities with hot climate and windless conditions, especially if the city is located on rugged terrain. Table 1 shows the cities with the highest number of windless periods during the hot season. Comparison and analysis of these data are used to assess the impact of temperature and windless conditions on the formation of unfavorable environment and to identify cities with extreme conditions.

\section{Materials and methods}

For analysis, three cities with the most extreme hot and windless conditions - Sochi, Makhachkala and Dushanbe - were selected. It is known that one of the main environmental and climatic factors that have a significant impact on the formation of the external and internal environment of urban space, along with air temperature, is wind. Wind has a significant effect on the state of air pollution in the city. The prevailing wind direction in a specific area in the surface air layer in rough terrain is determined not only by the general circulation of the atmosphere, but mainly by the direction of the ridges and valleys. Dense buildings in these cities in rough terrain lead to disruption of the natural aeration of the area [5]. As a result of this, stable zones with stagnation of air are formed in urban areas and areas with hot windless climate conditions and unfavorable environment. The combination of surface inversion with light winds is called a stagnant state of air and is one of the most unfavorable weather conditions, since in this case the microclimate parameters sharply aggravate, as well as the most intense accumulation of impurities in the lower atmosphere.

Based on the data of the Weather and Climate Information and Information Portal, it can be argued that the most extreme months for the cities of Sochi and Makhachkala are July, September, October and November. From Tables 2, 3 and Figures 1,2 it is seen that in the cities of Sochi and Makhachkala these months have high air temperatures at low wind speeds. The situation is exacerbated by the rapid growth of construction, an increase in population and the development of transport infrastructure. Under these conditions, cities located in the mountains, having insufficient aeration and high level of temperature and radiation heating, are subject to temperature inversions [6]. The dense high-rise construction characteristic of modern cities, preventing the natural aeration of urban space, creates an extreme environmental situation. In addition, under temperature inversions, an increase in temperature is observed at heights, and the upper floors of multi-storey buildings are in adverse climatic and environmental conditions. 
Table 1. Summer windless periods in cities of Central Asia, Kazakhstan and the Caucasus by the weather stations data.

\begin{tabular}{|c|c|c|}
\hline Cities (countries) & $\begin{array}{c}\text { The average number of windless } \\
\text { conditions in July \% }\end{array}$ & $\begin{array}{c}\text { The average number of } \\
\text { windless conditions from May } \\
15 \text { till September } 15, \%\end{array}$ \\
\hline 1 & 2 & 3 \\
\hline TAJIKISTAN & & \\
\hline Dushanbe & 59 & 43 \\
\hline Kurgan-Tyube & 34 & 21 \\
\hline Isfara & 39 & 25 \\
\hline Shaartuz & 37 & 32 \\
\hline Murghab & 42 & 38 \\
\hline Khorog & 40 & 37 \\
\hline \multicolumn{3}{|l|}{ UZBEKISTAN } \\
\hline Andijan & 38 & 34 \\
\hline Tashkent & 22 & 18 \\
\hline Denau & 26 & 24 \\
\hline Navoi & 32 & 30 \\
\hline Uchkurgan & 35 & 30 \\
\hline Ferghana & 37 & 34 \\
\hline \multicolumn{3}{|l|}{ KAZAKHSTAN } \\
\hline Alma-ata & 25 & 22 \\
\hline Jambul & 23 & 20 \\
\hline Karaganda & 21 & 19 \\
\hline Semipalatinsk & 31 & 28 \\
\hline \multicolumn{3}{|l|}{ GEORGIA } \\
\hline Batumi & 47 & 42 \\
\hline Tbilisi & 26 & 22 \\
\hline Tkibuli & 67 & 61 \\
\hline Tskaltubo & 64 & 59 \\
\hline \multicolumn{3}{|l|}{ RUSSIA } \\
\hline Sochi & 34 & 29 \\
\hline Makhachkala & 38 & 32 \\
\hline Kizlyar & 30 & 26 \\
\hline The terrible & 28 & 24 \\
\hline Gudermes & 26 & 28 \\
\hline Biysk & 24 & 21 \\
\hline
\end{tabular}

Table 2. Wind speed in the city of Sochi, $\mathrm{m} / \mathrm{s}$.

\begin{tabular}{|c|c|c|c|c|c|c|c|c|c|c|c|c|}
\hline Jan & Feb & Mar & Apr & May & Jun & Jul & Aug & Sep & Oct & Nov & Dec & $\begin{array}{c}\text { per } \\
\text { annum }\end{array}$ \\
\hline 2.0 & 1.9 & 1.8 & 1.6 & 1.5 & 1.5 & 1.5 & 1.6 & 1.6 & 1.7 & 1.8 & 1.9 & 1.7 \\
\hline
\end{tabular}




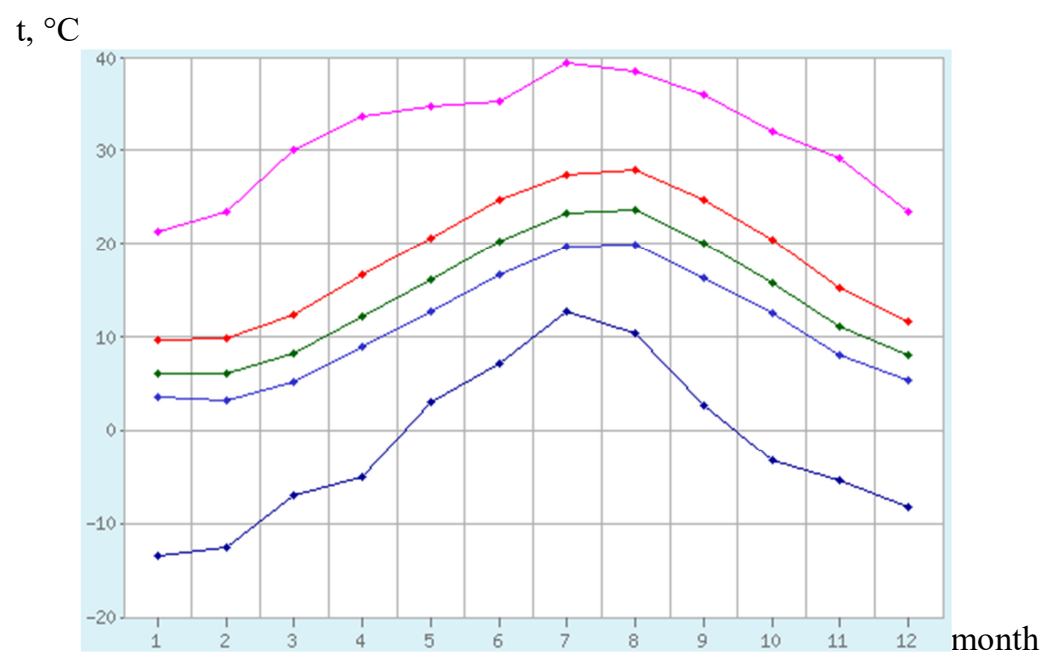

Fig. 1. Schedule of temperature changes in Sochi during the year.

Table 3. Wind speed in the city of Makhachkala, $\mathrm{m} / \mathrm{s}$.

\begin{tabular}{|c|c|c|c|c|c|c|c|c|c|c|c|c|}
\hline Jan & Feb & Mar & Apr & May & Jun & Jul & Aug & Sep & Oct & Nov & Dec & $\begin{array}{c}\text { per } \\
\text { annum }\end{array}$ \\
\hline 3.4 & 3.7 & 3.7 & 3.5 & 3.3 & 3.0 & 2.7 & 2.8 & 3.3 & 3.5 & 3.5 & 3.5 & 3.3 \\
\hline
\end{tabular}

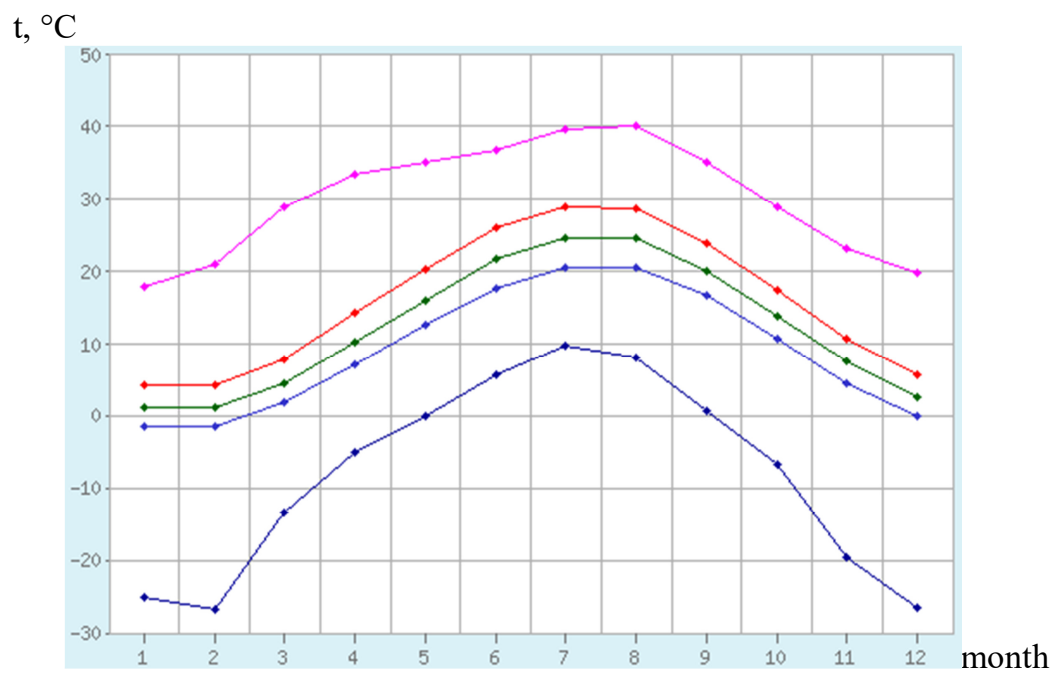

Fig. 2. Schedule of temperature changes in Makhachkala during the year.

Therefore, when planning a city, one has to pay attention to these factors. During construction design, in the areas with hot windless climate, it is important to take into account general circulation wind, as well as profiling local winds of a sloping, mountainvalley origin [6,7]. They can vary significantly at close distances and are susceptible to impact during development. The direction of the wind is determined by the areas of transport of all atmospheric pollution. Wind speed is largely determined by the building 
system. The prevalence of windless (calm) days in the cities of Central Asia and the Caucasus, the issue of natural ventilation of the residential area plays a greater role in the formation of a favorable ecology than in other cities of the CIS.

The climate analysis of the city of Dushanbe revealed that in the daytime high intensity of solar radiation (up to $810 \mathrm{~W} / \mathrm{m}^{2}$ on vertical and up to $940 \mathrm{~W} / \mathrm{m}^{2}$ on horizontal surfaces), significant air temperatures (absolute maximums up to $46^{\circ} \mathrm{C}$ ), light winds $(1 \ldots 3 \mathrm{~m} / \mathrm{s}$ ) and windless conditions predominate. The buildings have certain aerodynamic properties that depend on planning factors and public amenities. When air flows around buildings and dense green spaces, there is some inhibition and deformation of the wind flow. On windy days in the inhabited residential area, the wind speed decreases by $60-70 \%$, which contributes to the deposition of harmful emissions. At the same time, calm conditions are formed on the territory of low-wind cities with a wind flow speed of up to $2 \mathrm{~m} / \mathrm{s}$. Such a wind condition allows the development of weak air currents of thermal origin. The speed of such convective flows according to observations can reach up to $10 \mathrm{~m} / \mathrm{s}$. The formation of such convective flows can play a significant role in improving the ecology of the air basin of urban areas $[8,9]$.

The city of Dushanbe belongs to the foothills of Tajikistan. According to the climatic classification, this region is characterized by a dry climate with very warm summers, mild and moderate winters. Despite the proximity of the city to the mountains, the influence of the latter on the summer daytime thermal conditions of the city is insignificant. In Dushanbe, as in many cities in the region, light winds prevail, and windless conditions are very often observed, which makes up $40 \ldots 70 \%$ of cases of weather indicators.

However, in the southern cities in the summer, insulated surfaces of the walls of houses, artificial coatings and soil are heated to high temperatures $\left(+70 \ldots+75^{\circ} \mathrm{C}\right)$. Surfaces not exposed to solar radiation have a lower temperature $+20 \ldots+25^{\circ} \mathrm{C}$. The difference in temperature of the surface of the asphalt in the shade of trees and in the sun can be $20 \ldots 25$ ${ }^{\circ} \mathrm{C}$, which contributes to air flows in urban areas [10]. In conditions of low wind and nowind the air flows of thermal origin arise, which are of local circulation of air masses. The power of convective flows and their activity are directly proportional to the difference in heating of various adjacent surfaces. These provisions are confirmed by field observations made by us in the summer in the microdistricts of Dushanbe.

Thus, it can be argued that in the surface layers of the atmosphere, in the human occupation zone, heat-humidity and wind disturbances are formed that go beyond the climatic factors of this place with their indicators. These disturbances can be time-varying, geographically mobile and contrasting in the immediate vicinity. The speed of their occurrence or termination is closely related to the appearance or termination of insolation, as well as the type of active surface and its size. As a result, a real possibility arises of regulating the heat-wind conditions of residential buildings by combining the conditions of insolation of underlying surfaces and the energy activity of the latter [11,12] Based on the analysis, models for the formation of aeration of urban space were constructed (Fig. 3). 
a
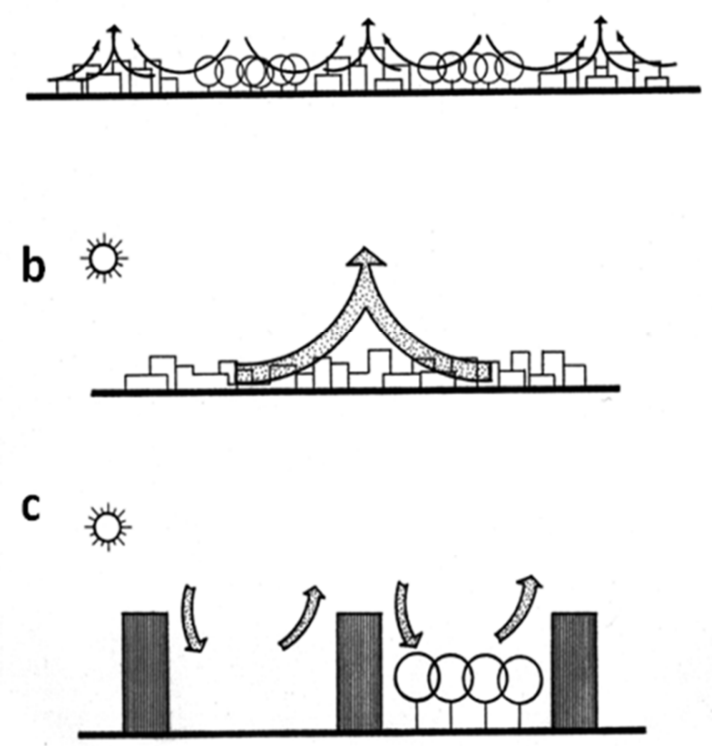

Fig. 3. Model for the formation of aeration: $a$ - in urban space combined with green areas; $b-$ in a densely built urban space; $c$ - in parts of urban area.

Consequently, it can be argued that in windless climate conditions, there are factors contributing to the natural aeration of the urban area. Building planning decisions, distance between buildings, orientation, insolation conditions are the determining factors in the formation of urban local winds, that is, natural aeration of buildings of thermal origin.

From an energy point of view, urban local winds can be attributed to the movement of free convection, developing under the influence of the forces of Archimedes. In order for them to develop, it is necessary that there is no general air transport capable of eliminating local free convection movements. Arising in the field of weakened circulation, urban local winds represent the movement of thermal convection. They are formed by thermal disturbances caused by the uniformity of heating and cooling of the active surface of the building and the air adjacent to it $[14,15]$. The resulting horizontal gradient temperatures (a green garden or square, an irradiated facade or a shadow facade, lakes or a construction site, etc.) are the cause of the appearance of local circulations. Thermal disturbances can be either periodic or continuous. Local periodic winds arise as a result of thermal disturbance of differently insulated active surfaces in the wind field of general circulation or when the latter is weakened or absent. In the absence of a general wind field, independent local air currents are formed on the territory of urban development due to thermal differences [16]. The conditions for the development of microbreeze circulation are all the more favorable, the greater this temperature contrast. Table 4 presents the results of a series of measurements made by meteorological observations.

The table shows the temperature difference between the surfaces of urban space, contributing to local air circulation. The conditions for the development of microbreeze circulation are all the more favorable, the greater this temperature contrast. Therefore, it can be argued that the cause of the development of local circulation on the inter-lane roads and streets is the temperature heterogeneity of the surface of the bridge and wood strips. Most clearly this phenomenon occurs at low wind speeds and windless conditions. In the 
daytime, the surface of the pavement overheats compared to the surface of wood strips. As a result of this, local air currents arise, moving along closed circuits, rising above the bridge and falling above forest belts during the day, and with reverse movement at night, thereby preventing the concentration of harmful substances in urban space.

Based on the studies, a model of the formation of thermal airflow for a yard space under different landscaping conditions is built Figure 4.

Table 4. Surface temperature in the area of Dushanbe.

\begin{tabular}{|l|c|}
\hline \multicolumn{1}{|c|}{ Surface character } & Temperature, ${ }^{\circ} \mathrm{C}$ \\
\hline Lake & 20.8 \\
Botanic garden & 27.5 \\
Central park & 46.8 \\
Open residential area & 64.2 \\
Densely built-up area & 50.4 \\
Open area of the community center & 68.4 \\
\hline
\end{tabular}

The table shows the temperature difference between the surfaces of urban space, contributing to local air circulation. The conditions for the development of microbreeze circulation are all the more favorable, the greater this temperature contrast. Therefore, it can be argued that the cause of the development of local circulation on the inter-lane roads and streets is the temperature heterogeneity of the surface of the bridge and wood strips. Most clearly this phenomenon occurs at low wind speeds and windless conditions. In the daytime, the surface of the pavement overheats compared to the surface of wood strips. As a result of this, local air currents arise, moving along closed circuits, rising above the bridge and falling above forest belts during the day, and with reverse movement at night, thereby preventing the concentration of harmful substances in urban space.

Based on the studies, a model of the formation of thermal airflow for a yard space under different landscaping conditions is built Figure 4.

This model shows that landscaping and inter-block space planning contribute to the formation of local meteorological processes and the emergence of air circulation of thermal origin. Local meteorological processes and phenomena in development play an important role in shaping the city's climate and microclimate. They create difficult conditions for natural local air circulation, transport and dispersion of pollution in the atmosphere, which improves the environment.

As a result, it can be noted that when considering the mechanism of formation of local winds, the developing local circulation has the following features:

(1) the presence of a sufficiently large temperature contrast of both two adjacent underlying surfaces and the layers of air above them;

(2) the presence of two layers of air in height, the direction of the wind in which when changing from one layer to another changes sharply, sometimes by $180^{\circ}$ (in high mountain areas the reverse flow may not be observed);

(3) frequent presence of a temperature inversion in the transition layer with weakening wind speed. 

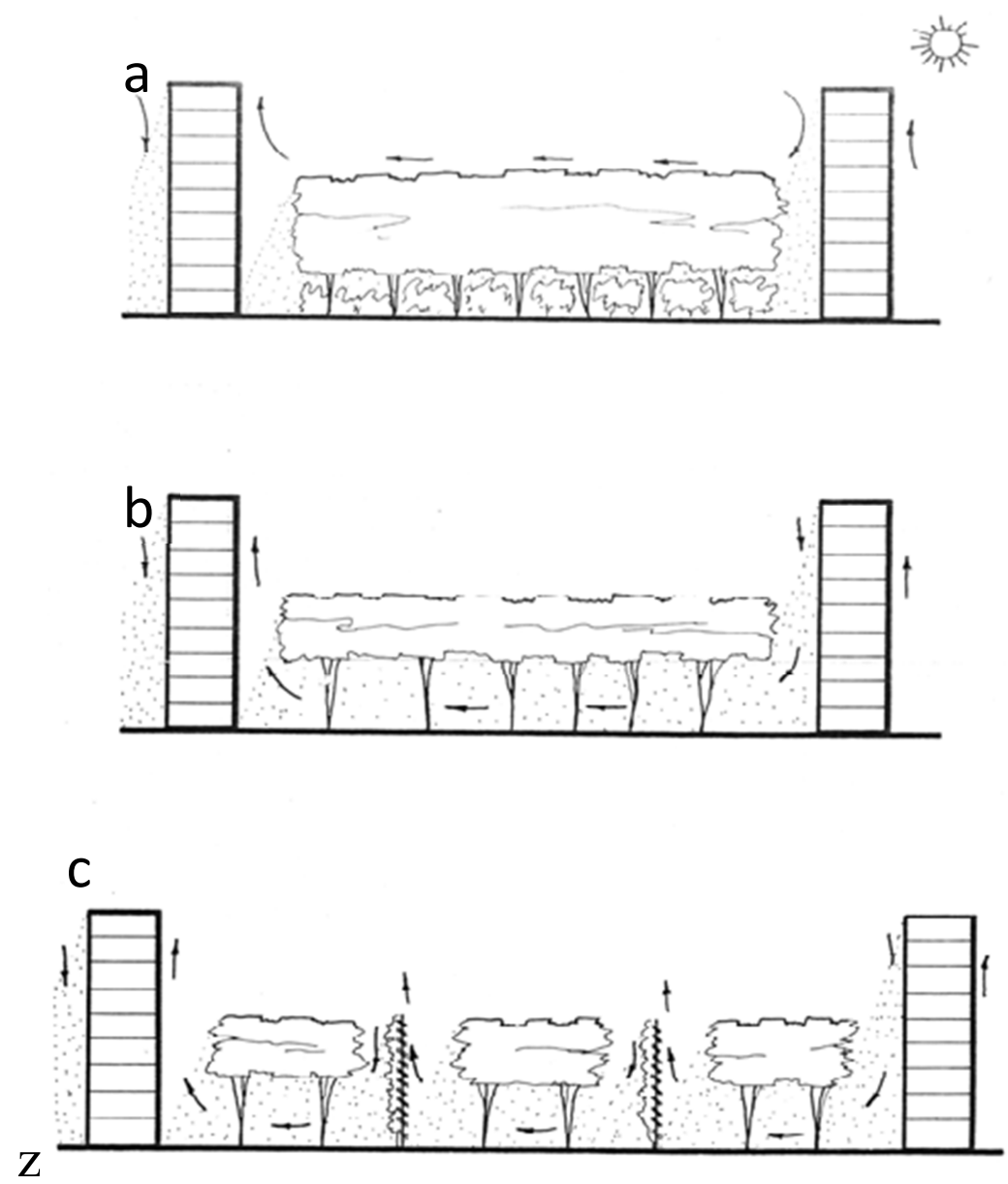

a- low-stemmed, large-crowned landscaping; b- high-stemmed, large-crowned landscaping; c- separation of a large space of the yard with louvered walls.

Fig. 4. The influence of the nature of the yard landscaping on the formation of air flow.

As it follows, in order to organize a systematic natural ventilation of the building territory and housing and thereby improve the microclimate, it is necessary to use the mechanism of interaction of insolation with the active surface of the building (surface of walls, coatings, driveways, sidewalks and walkways).

\section{Concludions}

1. In cities with hot and windless climate conditions located on a rugged terrain, an unfavorable environmental situation is formed in the process of urban development due to the lack of sufficient air aeration.

2. In windless conditions in an urban environment, factors contributing to natural aeration are observed.

3. Correctly selected planning decisions of buildings, distances between buildings, insolation conditions and orientation contribute to the formation of natural aeration of thermal origin. 
4. Due to temperature difference between the surfaces of urban space resulting from exposure to solar radiation, upward and downward convective flows that create air circulation in urban space are formed.

5. To improve the environment of the city located on a rugged terrain in hot and windless climate, it is necessary to take into account the conditions for the occurrence of natural aeration of thermal origin. With the development of urban construction, at the design stage, it is necessary to identify measures for the formation and regulation of the natural air circulation of urban space.

\section{References}

1. V.N. Pryahin, A.L. Bolsherotov, N.E. Rjazanova J. Vestnik RUDN, 3, 72-76 (2009)

2. R. C. Estoque, Yu.Murayama J. Photogram. Rem. Sens. 133, 18-29 (2017)

3. Xianghua Li, Jingyi Guo, Chao Gao, Zhen Su, Zili Zhang., Chaos, Solitons \& Fractals, 107, 256-265 (2018)

4. A. A Giyasov, Yu. G. Barotov, J. Jekologija, Urb. Ar., 3, 90-97 (2018)

5. A. A.Giyasov, Z. R. Tuskaeva, I. V. J Giyasova, Sustain. Mount. Develop.4(38), $558-565(2018)$

6. A. P. Cuesta-Mosquera, M. Wahl, J. G. Acosta-López, J. A. García-Reynoso, B. Helena, Aristizábal-Zuluaga, Sustain. Cit. Soc.,52, (2020), Article 101852

7. Cheng, Bin, Gou, Zhonghua, Zhang, Fan, Feng, Qiushuang, Huang, Zefeng. Sustain. Cit. Soc. 51 (2019), 101756. 10.1016/j.scs.2019.101756.

8. S. Attia, T. Lacombe, H. T. Rakotondramiarana, F. Garde, G. R. Roshan, Sustain. Cit. Soc.45, 8-24 (2019)

9. J. Niemelä, Landsc. Urb. Plan. 125, 298-303, (2014)

10. S. Kh. Karimov, Kh. M. Akhmedov, M. Abid, G. N. Petrov, Sci. Tot. Envir. 461462, 835-838 (2013)

11. Tao Chen, Anming Bao, Guli Jiapaer, Hao Guo, Latipa Tuerhanjiang, Sci Tot. Envir. 653, 1311-1325 (2019)

12. Y. Zhang, P.A. Meyers, X. Liu, G. Wang, B. Wen, Quarter. Sci. Rev. 152, 19-30 (2016).

13. B. Mannig, F. Pollinger, A. Gafurov, S. Vorogushyn, K. Unger-Shayesteh, Imp. Clim. Chan. Centr. Asia Encyclop. Anthrop., 2, 195-203 (2018)

14. V.L.Kashinceva, D.A.Leonova, T.B.Gijasov,Bill Constr. Equip. 12, 27-30 (2018)

15. Hyojoon Jeong, Misun Park, Wontae Hwang, Eunhan Kim, Moonhee Han, Annals Nucl. Ener. 55, 230-237 (2013)

16. Qun Wang, Yi Wang, Yifan Fan, Jian Hang, Yuguo Li, Build. Envir., 148, 433447 (2019) 